Copyright (C) 2021 by Cherkas Global University

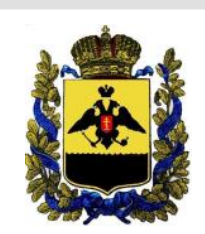

Published in the USA

Bylye Gody

Has been issued since 2006.

E-ISSN: $2310-0028$

2021. 16(4): 1594-1601

DOI: $10.13187 /$ bg.2021.4.1594

Journal homepage:

https://bg.cherkasgu.press

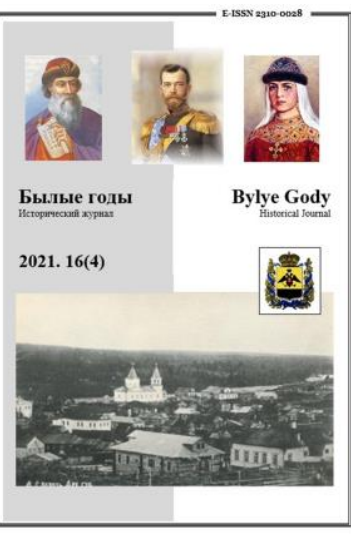

\title{
Regulatory Potential of the Positive and Customary Law of the Zyryans and Samoyeds in the Field of Environmental Management in the XVII - XVIII centuries
}

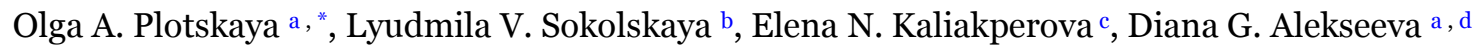 \\ a Financial University under the Government of the Russian Federation, Russian Federation \\ b State Humanitarian and Technological University, Russian Federation \\ c East Kazakhstan State University named after S. Amanzholova, Kazakhstan \\ d Kutafin Moscow State Law University (MSAL), Russian Federation
}

\begin{abstract}
Today, the interest of researchers in regional history has increased all over the world, especially to the history of the peoples of the Arctic zone of Russia. The purpose of this work is to study the regulatory potential of the positive and customary law of the Zyryans and Samoyeds in the use of land, water and forest resources in the XVII-XVIII centuries. The authors formulate the conclusion that the Arctic peoples under consideration have not lost their own identity, traditions and managed to preserve the regulatory force of customary law. In the XVII-XVIII centuries positive and customary law functioned in parallel on the territory of settlement of these peoples. The regulation of the sphere of nature management was aimed at preserving not only natural objects, but also the traditional system of life of ethno-local societies, as well as the established model of nature management. This trend appeared in the XV century. Since the XVII century, the legislator began to impose restrictions on the use of natural resources, legislatively allocating a list of protected, sovereign and other territories where the principle of freedom of use did not apply. By the end of the XVIII century, there is a tendency of mutual influence of the norms of positive and customary law in the field of environmental management. At that time, the customary law of the Arctic peoples supplemented the norms of positive law. The authors studied various historical documents, national folklore, mythological prose. An important source is archival documents, systematized in collections. Publications in the periodical press and pre-revolutionary normative legal acts of the Russian Empire systematized in the "Complete Collection of Laws of the Russian Empire» (PSZ), are attracted.
\end{abstract}

Keywords: Komi, Nenets, positive law, customary law, commercial law, Zyryans, Samoyeds.

\section{1. Введение}

В современных условиях нарастающей глобализации исследование значения и роли обычного права различных народов России, его соотношения с нормами позитивного (писаного) права представляется актуальным. Определенный научный интерес вызывает проблема познания обычного права финно-угорских (коми) и самодийских (ненцы) народов XVII-XVIII вв., так как, кроме историко-правового аспекта, важное значение данная тема приобретает для понимания существующих современных тенденций сохранения культуры природопользования, традиционных социокультурных аспектов развития, характерных не только для ненцев (самоедов дореволюционное название) и коми (зырян - устаревшее название, применявшееся до революции), но и для других народов, постоянно проживающих на территории Европейского северо-востока России (Арктической зоны России) и Зауралья (Sokolskaya, Valentonis, 2020).

\footnotetext{
${ }^{*}$ Corresponding author

E-mail addresses: olga.plockaya@mail.ru (O.A. Plotskaya), cokol4512@yandex.ru (L.V. Sokolskaya), elenamanina@mail.ru (E.N. Kaliakperova), alekseeva.dg@yandex.ru (D.G. Alekseeva)
} 
В связи с этим исследование особенностей регулятивного потенциала позитивного и обычного права зырян и самоедов в сфере природопользования в XVII-XVIII вв. как историко-правового явления, наделенного традиционным национальным обычно-правовым колоритом, а также выявляющего элементы правовой культуры и этнического менталитета, имеет не только теоретическое, но и существенное практическое значение.

Важно исследовать традиционный, складывавшийся на протяжении многих веков обычноправовой опыт в системе природопользования у зырян и самоедов, проживавших в значительной отдаленности от центральных регионов России в суровом климате. Эти народы вели традиционное хозяйство (многие из них до сих пор занимаются охотой, рыбалкой, оленеводством), сохранили своеобразие и неповторимость этнической правовой культуры, которая частично проявляется в самобытном обычном праве. Весомое место в нем всегда уделялось «промысловым» обычноправовым нормам.

В настоящее время в российской историко-правовой доктрине все больше внимания привлекается перспективам развития приполярных арктических и полярных районов России. Русский Север привлекает ученых своей традиционностью, которая сохранилась, благодаря в том числе и обычному праву, являвшемуся нормативно-стабилизирующим фактором, обеспечивавшим функционирование этнолокальных общностей северных народов.

\section{2. Материалы и методы}

Эмпирической основой исследования являются найденные авторами и введенные в научный оборот архивные документы Российского государственного архива древних актов (Москва, Российская Федерация), Национального архива Республики Коми (Сыктывкар, Российская Федерация), содержащие сведения о нормах и институтах обычного права, применявшихся в процессе жизнедеятельности этнолокального общества в рассматриваемый хронологический период. Документы официального делопроизводства, находящиеся на хранении в указанных архивах, являются важнейшими носителями исторической и этноправовой информации о функционировании норм обычного права. Кроме того, важным источником при раскрытии регулятивного потенциала позитивного и обычного права у исследуемых народов являются систематизированные сборники, содержащие не только архивные документы, но и памятники права (например, Коми край в XVIII веке, Историко-филологический сборник, Обдорский край и Мангазея в XVII веке). Особое значение имеет исследование законодательных актов Российской империи, систематизированных в «Полном собрании законов Российской империи».

К сожалению, до нас не дошли систематизированные писаные источники обычного права этих народов. О существовании «зырянского судебника» XVI в. упоминается в работе М. Михайлова (Михайлов, 1850: 242). Возможно, речь шла об источнике права, содержавшем зырянские правовые обычаи, но, к сожалению, его текст не найден. Поэтому обычно-правовой эмпирический материал исследуется «...благодаря сохранившимся русским документам» (Вершинин, Визгалов, 2004: 4), созданным в конкретный исторический период; правовым обычаям, отраженным в национальном фольклоре, мифологической прозе, ритуалах, играх. Процесс взаимовлияния действовавшего в то время законодательства и обычно-правовых норм, а также этнографический материал, раскрывающий правовые воззрения исследуемых народов, представлен в периодической печати. Поэтому в данной работе используются публикации из периодической печати в таких журналах, как «Вятские губернские ведомости», «Вологодские губернские ведомости», «Журнал министерства народного просвещения».

Методологический инструментарий проведенного исследования представлен в виде взаимосвязанных и взаимообусловленных научно-методических подходов, методов и принципов. Применение методов анализа и синтеза позволило исследовать эмпирическую основу и выделить закономерности функционирования норм позитивного и обычного права. Использование историкоправового и системного методов обеспечили возможность рассмотрения объекта исследования, учитывая исторические события и факты, существовавшие в обозначенных хронологических рамках, а также систематизировать их, выделяя общие тенденции. Герменевтический метод позволил представить толкование используемых в работе источников права, а также исторических архивных материалов.

\section{3. Обсуждение}

Среди дореволюционных исследователей, знакомивших читателей на страницах периодических изданий с элементами крестьянского этноправового мира, необходимо назвать О. Ежова, П. Ефименко, М. Михайлова и др. (Ежов, 1857; Ефименко, 1874; Михайлов, 1850).

В современной российской науке обычно-правовой быт, этнокультурное пространство отдельных приарктических народов, этноправо, а также особенности обычно-правовой культуры у различных этносов рассматриваются в рамках гуманитарных исследований. В этой связи необходимо отметить имена М.Б. Аверина, Н.С. Авдонина, Н.А. Алимбая, С.В. Березницкого, И.И. Галечко, К.С. Зайкова, П.В. Никитина, А.В. Поповой, С.А. Правкина, П.В. Примака, Б.К. Смагулова, В.В. Смирнова, В.В. Титова, Р.В. Шагиевой, М.А. Хватовой, А.Б. Храмцова и др. (Аверин и др., 2020;

$$
-1595-
$$


Алимбай, Смагулов, 2021; Березницкий, 2020; Зайков, Авдонина, 2019; Правкин и др., 2021; Титов, 2021; Храмцов, 2021 и др.).

В представленной литературе исследуются различные историко-теоретические аспекты жизнедеятельности народов России, однако фактически отсутствует анализ регулятивного потенциала позитивного и обычного права зырян и самоедов в сфере природопользования в XVIIXVIII вв.

Среди исследователей, внесших научный вклад в изучение обозначенной проблемы, важно отметить следующих: Е.В. Вершинина, Г.П. Визгалова, А.В. Головнева, В.А. Зибарева, П.А. Колесникова, Н.Д. Конакова (Вершинин, Визгалов, 2004; Головнев, 1995; Зибарев, 1986; Колесников, 1982; Конаков, 2004) и др. Несмотря на предпринятые попытки анализа некоторых обычно-правовых промысловых институтов и отношений, сведения о взаимодействии и сосуществовании позитивного и обычного права зырян и самоедов в сфере природопользования в XVII-XVIII вв. не систематизированы.

Поэтому целью настоящего исследования является изучение регулятивного потенциала общераспространенного позитивного и локализированного обычного права зырян и самоедов в сфере использования земельных, водных, лесных ресурсов в XVII-XVIII вв.

\section{4. Результаты}

Обычное право приарктических народов в сфере природопользования формировалось постепенно, так как российский законодатель предоставил им возможность регулировать возникавшие правоотношения нормами обычного права, «исходящего от самого народа». Так, в редких архивных источниках, относящихся к XV в., встречается информация о свободном пользовании автохтонными народами водными, лесными, земельными ресурсами. Статус земель традиционного проживания регламентировался обычным правом, и, кроме того, российский законодатель защищал эти земли, ограничивая их гражданский оборот (Жалованная..., 1958: 247; Жалованная грамота..., 1958: 255).

В XVI веке центральная власть предоставляла свободу в природопользовании исследуемым народам. Например, российский законодатель зафиксировал не только особые права в сфере пользования землями, на которых традиционно проживали самоеды, после принятия ими российского подданства, но и защиту со стороны государства «...от всяких людей оберегали..., в обиду не давали» (Жалованная грамота..., 2004: 10). Это способствовало увеличению регулятивного потенциала обычного права, которое регламентировало различные аспекты природопользования, в том числе и правонарушения, совершавшиеся в рассматриваемой сфере. Эмпирические источники свидетельствуют о появлении различных обычно-правовых правонарушений в сфере природопользования. Так, зырянская мифологическая проза упоминает о различных кражах, прежде всего объектов промысла, носивших характер товарного продукта, ввиду того, что Коми край с конца XIV века уже был включен в общероссийские рыночные отношения, в которых пушнина и объекты промысла приобретали характер товара (Электронная...); самоедская мифология раскрывает особенности регулирования обычноправовыми нормами оленеводческих отношений (Головнев, 1995: 289).

Еще путешественник Джильс Флетчер в XVI в. упоминал о том, что у зырян права собственности на земельные ресурсы не существовало, так как каждый мог трудиться на любом, не занятом другим человеком участке (Флетчер, 2007: 123). Эта тенденция, закрепленная нормами обычного права, сохранялась вплоть до н. XX века (НА РК. Ф. 273. Оп. 1. Д. 572. Л. 3; Д. 471. Л. 1-2; Ф. 130. ОП. 1. Д. 107. Л. 1-1 об.; РГАДА. Ф. 647. Оп. 1. Д. 14. Л. 1; Д. 6. Л. 1) и была описана М.А. Большаковым: «...Имелось ...одно основное убеждение: каждый имеет право приступать к труду на любом участке, не занятом трудом другого» (Большаков, 1907: 2).

Российский законодатель в XVII веке продолжил взятый в предыдущие века курс, но с некоторыми ограничениями. Он санкционировал свободное использование лесных, водных пространств, не относящихся к «засечныя и в и(ы)ныя заповедныя леса» (Соборное...) (Гл. VII ст. 23), к чужой собственности «но на чюжей земле лесу не росчищати...» (Соборное...) (Гл. Х ст. 239), к государевой собственности: «...в государевых прудех и в озерах рыбы на себя не ловити..., ему наказание учинити, что государь укажет» (Соборное...) (Гл. III ст. 8).

Обычное право, существуя параллельно с позитивным, также регламентировало вопросы природопользования. Оно касалось «процесса урегулирования взаимоприемлемых норм совместного природопользования в тундровой зоне...» (Конаков, 2004: 153).

В обычном праве даже существовали следующие императивные нормы: «если по вине пастуха происходила потеря оленей, то хозяин был вправе взыскать с него часть или половину убытка...» (Иванова, 2009: 31). Если происходил падеж оленьего стада, то пастуху дозволялось употребить мясо, возвратив оленьи шкуры хозяину; если пастух потерял оленей, то он обязан компенсировать убыток хозяину (Иванова, 2009: 31). Обычное право регулировало наемные отношения в сфере оленеводства. Часто заключаемые в устной форме обычно-правовые договоры найма ижемцами (коми) (собственниками оленей) ненцев-пастухов для выпаса оленеводческого стада обязательно выполнялись. 
«Народное» право регламентировало детали распределения промысловых территорий. Уненцев в XVII веке происходили даже драки по причине неравномерного распределения промысловых территорий, которые закреплялись, исходя из норм обычного права, за определенными представителями различных родов и семей: «...в леших промыслех почали у них быть меж себя драки...» (Челобитная аманата..., 2004: 38).

Промысловые территории, оленеводческие пастбища, собаки (Отписка..., 2004: 18) и особенно олени («животина») (Из грамоты..., 2004: 24) имели важное значение в жизни приарктических народов. Олени являлись транспортом (Отписка тобольского..., 2004: 34; Отписка березовского..., 2004: 46), одним из важнейших пищевых компонентов, из их шкур изготавливали одежду и чум (дом), рыночным товаром (Челобитная торгового..., 2004: 20). Исторические источники отражают процесс борьбы за оленей: «... карачейская самоядь и остяки... побрали... и самоядок, со всеми их животами и с оленьми» (Отписка пустозерского..., 2004: 45); за обладание иными промысловыми предметами, использовавшимися в охоте, рыбной ловле, включая «...неводы, и сети, и лотки..., и якори...» (Из грамоты..., 2004: 23).

Рыболовство являлось достаточно важным занятием в жизни исследуемых народов (НА РК. Ф. 292. Оп. 1. Д. 3. Л. 3). Существовали своеобразные рыболовные угодья, которые находились на небольших реках. Так, В.А. Зибарев отметил, что «лов рыбы на таких водоемах был свободным... Однако у каждой семьи имелись свои постоянные, привычные места» (Зибарев, 1986: 177). Также функционировал простой правовой обычай: «Где остановился, там и добывай» (Зибарев 1986: 177). Но, если человек вложил труд в расчистку этой промысловой территории «или ставил постоянно ловушки..., то получал право на владение ими, которое могло передаваться по наследству» (Зибарев, 1986: 177). Данный процесс регулировался исключительно нормами обычного права. Ж.Б. Иванова отмечает, что в персональном индивидуальном пользовании находились речные участки, «...если там сооружались рыболовные запруды» (Иванова, 2009: 22-23). Кроме того, законодатель санкционировал этот процесс: «также кто будет бить челом о старых рыбных ловлях, о переоброчке или вновь на оброк: и те рыбные ловли отдавать на оброк из наддачи, справясь с прежними откупщиками, или владельцами, для того, чтобы старые откупщики и владельцы при переоброчке тех рыбных ловель и про новую отдачу ведали» (Статьи...).

Самоедов даже искали по месту расположения их рыболовных угодий. В зимнее время они перекочевывали, «переходя на оленях с места на место...» (Отписка березовского..., 2004: 46), а в летнее время находились на территории рыболовных угодий, принадлежащих роду: «...тое самоядь... выезжает для рыбных ловлей край моря и живет по островам» (Отписка березовского..., 2004: 46).

Охота также повсеместно была распространена у северных народов. О ее масштабах свидетельствуют фразы, сохранившиеся в исторических документах: «лешие промыслы, беличья охота, мягкая рухлядь, птичные шутики, лесно-звериный промысел» (Челобитная..., 2004: 21) и др. Лесная добыча не только употреблялась в пищу, но и продавалась либо обменивалась (Грамота из..., 2004: 12-13), ею также уплачивали ясак (подати, сборы) (Челобитная торгового..., 2004: 20). Ненцы даже особо ценную пушнину «...рухлядь многую - соболи добрые и лисицы и бобры...» (Челобитная..., 2004: 40) использовали, выкупая своих сородичей из заложников.

Обычное так же, как и позитивное право, защищало интересы и права охотника и «собственника добычи», так как добытый объект промысла считался неприкосновенным. Законодатель особенно отстаивал права охотника на пойманную добычу. Такая норма была закреплена даже в Соборном Уложении 1649 г.: «А будет кто такую птичью чюжую приваду испортит, измажет дехтем... или куропотную сетку украдет..., за то, что он ту птичью приваду испортит, учинить ему наказанье, бить батоги нещадно...» (Гл. Х ст. 217) (Соборное...).

Обычное право, в отличие от позитивного, регулировало нормы-табу. В промысловых обычноправовых отношениях часто применялись табуированные нормы. Это касалось особенностей поведения охотников и рыбаков на промысле. Его действия регулировались обычно-правовыми нормами, синкретизированными с религиозно-моральными и магическими нормами. В итоге весь комплекс этих норм закреплялся в табу и подлежал обязательному исполнению. Считалось, что за его нарушение последуют не только наказание со стороны членов этнолокального общества, но и сверхъестественные проклятия, что в свою очередь закреплялось принципом неотвратимости наказания. Так, к примеру, запрещалось уничтожать лишние деревья, неуважительно относиться к добыче, ругаться на промысле, произносить слова, неприятные духам-хозяевам леса, воды и т.д.

Необходимо отметить, что обычное право зырян и самоедов в XVII-XVIII вв., регулируя промысловые отношения, не противоречило нормам писаного права, оно дополняло позитивное право в тех вопросах, которые не были последним детально урегулированы. Российский законодатель в XVIII веке не устанавливал запретов на применение этнического обычного права, наоборот, он даже защищал естественные права самоедов на ведение промысловой деятельности в их родовых угодьях: «... и мне Самоядцов... всех пожаловать, дати б им на те рыбныя ловли и на звериныя ухожьи, Своя грамота жалованная, чтоб у них в те рыбныя ловли и звериныя ухожьи Печеряне и Пермяки впредь не вступалися...» (Грамота...). 
Автохтонным народам, проживавшим в приарктической зоне, позволялось осуществлять процедуру судопроизводства, в том числе и по вопросам природопользования, используя «собственное право». Возникавшие споры предлагалось рассматривать старожилами, которые вполне могли руководствоваться нормами обычного права: «...при размежевании земель от владельцов учинятся споры... и тот спор разбирать старожилами...» (Инструкция межевщикам...). Они руководствовались, «во-первых, собственным рассуждением, во-вторых, порядком, оставленным от прежде бывших родоначальников, в-третьих, наставлениями и внушениями по сей части земского начальства» (Зибарев, 1986: 76-77).

C конца XVIII века крестьянам законодательно было запрещено беспрепятственно распоряжаться земельными участками. Связано это было с осуществлением процесса Генерального межевания (Инструкция межевщикам...; Инструкция Межевым...). Несмотря на запрет, крестьяне, руководствуясь обычно-правовыми представлениями (НА РК. Ф. 99. Оп. 1. Д. 492. Л. 9; Д. 156. Л. 1; Д. 71. Л. 60; Ф. 273. Оп. 1. Д. 3. Л. 15 об.; Ф. 100. Оп. 1. Д. 953. Л. 1), относились к земле как к своему имуществу: «По доношению Яренского уезда Койгородской волости от крестьянн... имеют на собственных их деревенских участках...» (Коми край, 2012: 60). Территориальная отдаленность от центральных органов власти, незначительный государственный контроль позволяли, к примеру, зырянам, применявшим, прежде всего, нормы обычного права, свободно владеть и пользоваться не только земельными ресурсами (РГАДА. Ф. 966. Оп. 1. Д. 4. Л. 1), но и охотничьими, рыболовнопромысловыми угодьями. Подобные земли в архивных документах получили даже особое название «дедины и отчины», или «вековечные дедовские» (Рапорт в Яренскую, 2012: 68), так как из века в век передавались по наследству.

Однако законодатель понимал важность земельных, водных, лесных объектов в жизнедеятельности рассматриваемых народов, поэтому в 1789 г. были законодательно санкционированы послабления для государственных крестьян, так как им предоставлялась возможность «променивать и покупать... земли...» (О наблюдении...), в 1797 г. решилась проблема «малоимения» (Наказ крестьян..., 2012: 45) земель у государственных крестьян (О наполнении...) и др.

Наметившуюся тенденцию во второй половине XVIII в. П.А. Колесников обозначил как «...взаимовлияние и определенная взаимозависимость между государственным законодательством и общественным сознанием крестьянства» (Колесников, 1982: 166).

\section{5. Заключение}

Таким образом, в XVII-XVIII вв. на территории расселения коми и ненцев параллельно функционировало позитивное и обычное право. В обычном праве промысловые нормы систематизировались в «неписаный кодекс» обычно-правовых, табуированных и моральнонравственных установок. Регулирование сферы природопользования было направлено на сохранение не только природных объектов, но и традиционной системы жизнедеятельности этнолокальных обществ, а также устоявшейся модели природопользования. Эта тенденция появилась еще в XV веке. Начиная с XVII века, законодатель начал вводить ограничения пользования природными ресурсами, законодательно выделяя перечень заповедных, государевых и иных территорий, на которых не распространялся принцип свободы пользования. К концу XVIII века появляется тенденция взаимовлияния норм позитивного и обычного права в сфере природопользования. В это время обычное право приарктических народов дополняло нормы позитивного права.

\section{Литература}

Большаков, 1907 - Больщаков М.A. Община у зырян. СПб.: Типография М.П.С.

(Т-ва И.Н. Кушнерев и К), 1907. 107 с.

Вершинин, Визгалов, 2004 - Вершинин E.B., Визгалов Г.П. Обдорский край и Мангазея в XVII веке. Сборник документов. Екатеринбург: Издательство «Тезис», 2004. 200 с.

Головнев, 1995 - Головнев A.B. Говорящие культуры: традиции самодийцев и угров. Екатеринбург: Институт истории и археологии УрО РАН, 1995. 600 с.

Ежов, 1857 - Ежов О. Личность и отличительные качества зырян // Вятские губернские ведомости. 1857. № 22. С. 134-137.

Ефименко, 1874 - ЕФименко П. Юридические знаки // Журнал министерства народного просвещения. СПб., 1874. № 10. С. 53-170.

Зибарев, 1986 - Зибарев В.А. Из истории обычного права народов Севера // Советская этнография. 1986. № 2. С. 73-79.

Иванова, 2009 - Иванова Ж.Б. Религиозные и обычно-правовые традиции народов Северной России в охране среды обитания // Актуальные вопросы образования и науки. 2009. № 1-2. С. 30-31.

Историко-филологический..., 1958 - Историко-филологический сборник. Вып. 4. Сыктывкар: Коми филиал АН СССР, 1958. 272 с.

ПС3 РИ - IV - Полное собрание законов Российской империи. Собр. 1. T. IV. CПб., 1830. № 2007. С. 276-278. 
ПС3 РИ - IV - Полное собрание законов Российской империи. Собр. 1. T. IV. СПб., 1830. № 2139. C. 369-374.

ПСЗ РИ - XIV - Полное собрание законов Российской империи. Собр. 1. T. XIV. СПб., 1830. №10237. C. 104-161.

ПСЗ РИ - XVII - Полное собрание законов Российской империи. Собр. 1. T. XVII. СПб., 1830. № 12659 . С. 716-734.

ПСЗ РИ - XXIII - Полное собрание законов Российской империи. Собр. 1. Т. XXIII. СПб., 1830. № 16813 . C. $89-93$.

ПСЗ РИ - XXIV - Полное собрание законов Российской империи. Собр. 1. T. XXIV. СПб., 1830. № 18256 . С. $807-808$.

Колесников, 1982 - Колесников П.А. Воздействие народных масс на государственное законодательство России XVII-XVIII вв. // Проблемы истории крестьянства Европейской части России (до 1917 г.): Межвузовский сборник научных статей. Пермь, 1982. С. 158-174.

Конаков, 2004 - Конаков Н.Д. Традиционная система природопользования и хозяйственные занятия коми // Зырянский мир. Очерки о традиционной культуре коми народа. Сыктывкар: Коми книжное издательство, 2004. С. 65-181.

Михайлов, 1850 - Михайлов М. Усть-Вымь // Вологодские губернские ведомости. 1850. № 22. C. $242-243$.

Коми край в XVIII веке... - Коми край в XVIII веке: Сб. документов / Под общ. ред.

А.К. Гагиевой. Сыктывкар: КРАГСиУ, 2012. 115 с.

НА РК - Национальный архив Республики Коми.

РГАДА - Российский государственный архив древних актов.

Соборное... - Соборное Уложение 1649 года. [Электронный ресурс]. URL: http://www.hist.msu.ru/ ER/Etext/1649/whole.htm (дата обращения: 23.09.2021).

Флетчер, 2007 - Флетчер Д. О государстве Русском или образ правления русского царя с описанием нравов и обычаев жителей этой страны // Савельева Э.А., Королев К.С. Письменные известия о народе коми. Сыктывкар: Эском, 2007. С. 119-124.

Электронная... - Электронная библиотека «Энциклопедия уральских мифологий. Мифология коми» / ИЯЛИ Коми НЦ УрО РАН. [Электронный ресурc]. URL: http://www.komi.com/folk/myth/31.htm (дата обращения: 08.05.2014).

Alimbay, Smagulov, 2021 - Alimbay, N.A., Smagulov, B.K. (2021). Contribution of Russian Researchers in the Collection and Study of Materials on the Customary Law of the Kazakhs (late 18th - early 2oth centuries). Bylye Gody. 16(1): 85-96.

Averin et al., 2020 - Averin M.B., Nikitin P.V., Popova A.V. The role of the Ministry of Justice in improving the judicial system of the national outskirts of the Russian Empire (late 19th century - 1914) // Bylye Gody. 2020. 55(1): 162-172.

Bereznitsky et al., 2020 - Bereznitsky S.V., Galechko I.I., Primak P.V. Laws of the Russian Empire and hunting of the indigenous peoples of Siberia // Bylye Gody. 2020. 55(1): 31-39.

Pravkin et al., 2020 - Pravkin S.A., Smirnova V.V., Shagieva R.V., Khvatova M.A. Model of Conciliatory Law and Social Cooperation S.M. Solovyov as a Contribution to the Development of the Concept of the State (Law) School in Russian Historiography // Bylye Gody. 2021. 16(2): 620-628.

Sokolskaya, Valentonis, 2020 - Sokolskaya L., Valentonis A. The history of the acculturation concept // Journal of Intercultural Communicationthis. 2020. 20(3): 31-43.

Titov, 2021 - Titov V.V. Formation of the All-Russian Imperial identity in the Grand Duchy of Finland in the Reign of Alexander III: historical contexts and Political constraints // Bylye Gody. 2021. 16(1): 138-145.

Khramtsov, 2021 - Khramtsov A.B. Results and Prospects of Studying the Process of Settlement and Development of Crafts in the Southern Settlements of the Trans-Urals (late XVIII - early XX centuries) // Bylye Gody. 2021. 16(1): 74-84.

Zaikov, Avdonina, 2019 - Zaikov K.S., Avdonina N.S. Ethnic and Cultural Space of the Eastern Sami (Skolts) of the Northern Frontier of Russia and Norway-Denmark in the XVIII century // Bylye Gody. 2019. 51(1): 29-40.

\section{References}

Alimbay, Smagulov, 2021 - Alimbay, N.A., Smagulov, B.K. (2021). Contribution of Russian Researchers in the Collection and Study of Materials on the Customary Law of the Kazakhs (late 18th - early 2oth centuries). Bylye Gody. 16(1): 85-96.

Averin et al., 2020 - Averin, M.B., Nikitin, P.V., Popova, A.V. (2020). The role of the Ministry of Justice in improving the judicial system of the national outskirts of the Russian Empire (late 19th century 1914). Bylye Gody. 55(1): 162-172.

Bereznitsky et al., 2020 - Bereznitsky, S.V., Galechko, I.I., Primak, P.V. (2020). Laws of the Russian Empire and hunting of the indigenous peoples of Siberia. Bylye Gody. 55(1): 31-39.

Bolshakov, 1907 - Bolshakov, M.A. (1907). Obshchina u zyryan [The community of the Zyryans]. SPb. [in Russian] 
Efimenko, 1874 - Efimenko, P. (1874) Yuridicheskie znaki Legal signs [Legal signs]. Zhurnal ministerstva narodnogo prosveshcheniya. 10: 53-170. [in Russian]

Elektronnaya... - Elektronnaya biblioteka «Enciklopediya ural'skih mifologij. Mifologiya komi» [Electronic library "Encyclopedia of Ural mythologies. Komi Mythology". IYALI Komi NC UrO RAS]. [Electronic resource]. URL: http://www.komi.com/folk/myth/31.htm (date of accessed: 08.05.2014).

Fletcher, 2007 - Fletcher, D. (2007). O gosudarstve Russkom ili obraz pravleniya russkogo carya s opisaniem nravov i obychaev zhitelej etoj strany [Russian state or the image of the rule of the Russian tsar with a description of the customs and customs of the inhabitants of this country]. Pis'mennye izvestiya o narode komi: 119-124. [in Russian]

Golovnev, 1995 - Golovnev, A.V. (1995). Govoryashchie kul'tury: tradicii samodijcev i ugrov. [Speaking cultures: traditions of Samoyeds and Ugrians]. Yekaterinburg. [in Russian]

Istoriko-filologicheskij..., 1958 - Istoriko-filologicheskij sbornik [Historical and philological collection]. Syktyvkar, 1958. [in Russian]

Ivanova, 2009 - Ivanova, Zh.B. (2009). Religioznye i obychno-pravovye tradicii narodov Severnoj Rossii v ohrane sredy obitaniya [Religious and customary legal traditions of the peoples of Northern Russia in the protection of the habitat]. Aktual'nye voprosy obrazovaniya i nauki. 1-2: 30-31. [in Russian]

Khramtsov, 2021 - Khramtsov, A.B. (2021). Results and Prospects of Studying the Process of Settlement and Development of Crafts in the Southern Settlements of the Trans-Urals (late XVIII - early XX centuries). Bylye Gody. 16(1): 74-84.

Kolesnikov, 1982 - Kolesnikov, P.A. (1982) Vozdejstvie narodnyh mass na gosudarstvennoe zakonodatel'stvo Rossii XVII - XVIII vv. [The impact of the masses on the state legislation of Russia of the XVII-XVIII centuries]. Problemy istorii krest'yanstva Evropejskoj chasti Rossii (do 1917 g.): 158-174. [in Russian]

Komi Krai..., 2012 - Komi Krai in the XVIII century: collection of documents (2012). [Komi Krai in the XVIII century: collection of documents]. Syktyvkar. [in Russian]

Konakov, 2004 - Konakov, N.D. (2004). Tradicionnaya sistema prirodopol'zovaniya i hozyajstvennye zanyatiya komi [The traditional system of nature management and economic occupations of Komi] Zyryanskij mir. Ocherki o tradicionnoj kul'ture komi naroda: 65-181. [in Russian]

Mikhailov, 1850 - Mikhailov, M. (1850). Ust'-Vym' [Ust-VYM]. Vologodskie gubernskie vedomosti. 22: 242.

ON the RK - Nacional'nyj arhiv Respubliki Komi [The National Archive of the Komi Republic].

Polnoe sobranie..., 1830 - Polnoe sobranie zakonov Rossiiskoi imperii [Complete collection of laws of the Russian Empire]. Sobr. 1. T. IV., SPb. Pp. 369-374. [in Russian]

Pravkin et al., 2020 - Pravkin, S.A., Smirnova, V.V., Shagieva, R.V., Khvatova, M.A. (2020). Model of Conciliatory Law and Social Cooperation S.M. Solovyov as a Contribution to the Development of the Concept of the State (Law) School in Russian Historiography. Bylye Gody. 16(2): 620-628.

PSZ RI - IV - Polnoe sobranie zakonov Rossiiskoi imperii [Complete collection of laws of the Russian Empire]. Sobr. 1. T. IV. SPb., 1830. № 2007. Pp. 276-278. [in Russian]

PSZ RI - IV - Polnoe sobranie zakonov Rossiiskoi imperii [Complete collection of laws of the Russian

Empire]. Sobr. 1. T. IV. SPb., 1830. № 2139. Pp. 369-374. [in Russian]

PSZ RI - XIV - Polnoe sobranie zakonov Rossiiskoi imperii [Complete collection of laws of the

Russian Empire]. Sobr. 1. T. XIV. SPb., 1830. №10237. Pp. 104-161. [in Russian]

PSZ RI - XVII - Polnoe sobranie zakonov Rossiiskoi imperii [Complete collection of laws of the

Russian Empire]. Sobr. 1. T. XVII. SPb., 1830. № 12659. Pp. 716-734. [in Russian]

PSZ RI - XXIII - Polnoe sobranie zakonov Rossiiskoi imperii [Complete collection of laws of the

Russian Empire]. Sobr. 1. T. XXIII. SPb., 1830. № 16813. Pp. 89-93. [in Russian]

PSZ RI - XXIV - Polnoe sobranie zakonov Rossiiskoi imperii [Complete collection of laws of the

Russian Empire]. Sobr. 1. T. XXIV. SPb., 1830. № 18256. Pp. 807-808. [in Russian]

RGADA - Rossijskij gosudarstvennyj arhiv drevnih aktov [Russian State Archive of Ancient Acts].

Sokolskaya, Valentonis, 2020 - Sokolskaya, L., Valentonis, A. The history of the acculturation

concept. Journal of Intercultural Communicationthis. 20(3): 31-43.

Titov, 2021 - Titov, V.V. (2021). Formation of the All-Russian Imperial identity in the Grand Duchy of

Finland in the Reign of Alexander III: historical contexts and Political constraints. Bylye Gody. 16(1): 138-145.

Titov, 2021 - Titov, V.V. (2021). Formation of the All-Russian Imperial identity in the Grand Duchy of

Finland in the Reign of Alexander III: historical contexts and Political constraints. Bylye Gody. 16(1): 138-145.

Vershinin, Vizgalov, 2004 - Vershinin, E.V., Vizgalov, G.P. (2004). Obdorskij kraj i Mangazeya v

XVII veke [Obdorsky Krai and Mangazeya in the XVII century. Collection of documents]. Yekaterinburg.

[in Russian]

Yezhov, 1857 - Yezhov, O. (1857). Lichnost' i otlichitel'nye kachestva zyryan [Personality and distinctive qualities of zyryans]. Vyatskie gubernskie vedomosti. 22: 134-137. [in Russian]

Zaikov, Avdonina, 2019 - Zaikov, K.S., Avdonina, N.S. (2019). Ethnic and Cultural Space of the Eastern Sami (Skolts) of the Northern Frontier of Russia and Norway-Denmark in the XVIII century. Bylye Gody. 51(1): 29-40. 
Zibarev, 1986 - Zibarev, V.A. (1986). Iz istorii obychnogo prava narodov Severa [From the history of customary law of the peoples of the North]. Sovetskaya etnografiya. 2: 73-79. [in Russian]

\title{
Регулятивный потенциал позитивного и обычного права зырян и самоедов в сфере природопользования в XVII-XVIII вв.
}

\author{
Ольга Андреевна Плоцкая a , *, Людмила Викторовна Сокольская b, Елена Николаевна Калиакперова с \\ Диана Геннадьевна Алексеева ${ }^{\text {a }} \mathrm{d}$ \\ а Финансовый университет при Правительстве Российской Федерации, Российская Федерация \\ b Государственный гуманитарно-технологическогий университет, г. Орехово-Зуево, \\ Российская Федерация \\ c Восточно-Казахстанский государственный университет им. С. Аманжолова, \\ Усть-Каменогорск, Казахстан \\ d Московский государственный юридический университет им. О.Е. Кутафина (МГЮА), \\ Российская Федерация
}

Аннотация. Сегодня во всем мире возрос интерес исследователей к региональной истории, особенно к истории народов арктической зоны России. Целью данного исследования является изучение регулятивного потенциала позитивного и обычного права зырян и самоедов в сфере использования земельных, водных и лесных ресурсов в XVII-XVIII вв. Авторы формулируют вывод о том, что рассматриваемые приарктические народы не утратили собственной самобытности, традиционности, сумели сохранить регулирующую силу обычного права. В XVII-XVIII вв. на территории расселения этих народов параллельно функционировало позитивное и обычное право. Регулирование сферы природопользования было направлено на сохранение не только природных объектов, но и традиционной системы жизнедеятельности этнолокальных обществ, а также устоявшейся модели природопользования. Эта тенденция появилась еще в XV веке. Начиная с XVII века, законодатель начал вводить ограничения в пользовании природными ресурсами, законодательно выделяя перечень заповедных, государевых и иных территорий, на которые не распространялся принцип свободы пользования. К концу XVIII века появляется тенденция взаимовлияния норм позитивного и обычного права в сфере природопользования. В это время обычное право приарктических народов дополняло нормы позитивного права. Авторами были исследованы различные исторические документы, национальный фольклор, мифологическая проза. Важным источником являются архивные документы, систематизированные в сборники. Привлекаются публикации в периодической печати и дореволюционные нормативные правовые акты Российской империи, систематизированные в «Полном собрании законов Российской империи» (ПСЗ).

Ключевые слова: коми, ненцы, позитивное право, обычное право, промысловое право, зыряне, самоеды.

\footnotetext{
* Корреспондирующий автор

Адреса электронной почты: olga.plockaya@mail.ru (О.А. Плоцкая), cokol4512@yandex.ru (Л.В. Сокольская), elenamanina@mail.ru (Е.Н. Калиакперова), alekseeva.dg@yandex.ru (Д.Г. Алексеева)
} 